\title{
COVID-19 and Compliance with Awareness Programmes/Preventive Measures: A Case Study of Ibadan North Local Government, Oyo State, Nigeria
}

\author{
Mary Olufunke Adedokun ${ }^{1}$, Adenike Olayinka Kolawole ${ }^{2}$, Comfort Wuraola Adeyemo ${ }^{2}$, Gladys Modupe \\ Kayode $^{3} \&$ O. M. Bolarinwa ${ }^{4}$ \\ ${ }^{1}$ Department of Adult Education and Community Development, Ekiti State University, Ado Ekiti, Ekiti State, \\ Nigeria \\ ${ }^{2}$ Department of Educational Management, Ekiti State University, Ado-Ekiti, Nigeria \\ ${ }^{3}$ Department of Human Kinetics and Health Education, Ekiti State University, Ado Ekiti, Nigeria \\ Correspondence: Mary OlufunkeAdedokun, Department of Adult Education and Community Development, Ekiti \\ State University, Ado Ekiti, Ekiti State, Nigeria. E-mail: mary.adedokun@eksu.edu.ng
}

Received: July 13,2020 Accepted: August 30, 2020 Online Published: September 30, 2020

doi:10.5539/jms.v10n2p70 URL: https://doi.org/10.5539/jms.v10n2p70

\begin{abstract}
The study was carried out to examine the compliance of people to awareness programmes/preventive measures on COVID-19. The study was carried out in Ibadan North Local Government Area of Oyo State with the population being the residents of Ibadan North Local Government area. The study employed a descriptive design of the survey type. A self-designed questionnaire was used to elicit responses from respondents through purposive sampling method via Google form; sent to 400 respondents out of which 200 copies of questionnaire which were filled in a valid form were used for the study. Descriptive statistics of mean and standard deviation with appropriate remarks were used to analyse the research questions while T-test was used to analyze hypotheses 1-3 and ordinary least squares regression was used to analyse hypothesis 4 . The study showed that there existed a strong relationship between awareness programmes/preventive measures on COVID-19 and compliance of Ibadan North Local Government area citizens; that there existed a low significant relationship between medium of information and compliance of people to awareness/preventive measures on COVID-19 as indicated in $(\mathrm{r}=0.811, \mathrm{P}=.000<0.05)$ and among others the study revealed that awareness programmes, medium of information and preventive measures had $\left(\mathrm{P}=0.05, \mathrm{R}=0.993, \mathrm{R}^{2}=0.976\right.$, Adjusted $\mathrm{R}^{2}=0.986, \mathrm{~F}=$ 4707.2; Sig = 0.000); which showed that these dependent variables had significant relationship with people's compliance to awareness programmes on COVID-19.

Among the recommendations made were that government of Oyo State in particular and Nigeria in general should heighten the process of awareness programmes, provide materials that would help in taking preventive measures to indigent people and educate people on the lookout for verified and certified information from real authoritative sources as opposed to subscribing to fake news.
\end{abstract}

Keywords: Covid-19, awareness/preventive measures, education, sources of information, behavioral change

\section{Introduction}

Infectious diseases that cause death, disability and social and economic imbalance as well as political disruptions of accusations and counter accusations are major problems to humanity. At the early discovery of any infectious disease, the body responsible for disease control and prevention are expected to swing into action with the aim of stopping the rapid spread of the disease through the process by which various awareness programmes and preventive measures are anchored and spread to the nooks and crannies of the countries where the disease ravages. This presupposes giving people adequate education and precautions to reduce their chances of being infected and thereby curtailing its spread. Putting an end to the spread of infectious disease calls for community education through awareness programmes. Community education will make people to be aware of the conditions of the disease, its symptoms and preventive measures to make them not to be infected. People who are aware will do a critical analysis of the situation and come up with good solutions as to keep themselves safe (Adedokun, 1998). 
Awareness programmes in case of COVID-19 becomes important as Baker (1990) in Adedokun (1998) states that without education development cannot occur and that only an educated people can command the skills necessary for good health which will transcend into sustainable health and economic growth. It is, therefore, necessary to expand the knowledge base of people and enable them to understand and undertake measures to prevent themselves from contacting diseases fora healthy and sustainableliving. In this case education will be perceived to be positively related to living a healthy life free of diseases. Through awareness programmes,people would develop new behavioural attitudes that will produce new knowledge in them to make them keep safe in this pandemic era. The new knowledge brought about will change their negative views about the pandemic. The awareness programmes on COVID-19 should not be an exclusive right of some while others are being placed at disadvantage. The right to awareness programmes must be for all through various media and person to person, mouth to mouth education. This is because when some members of a given community are educated, they are able to promote the education of others and further the course of the health of others and the health of the nation as a whole.

Education (awareness programmes) bringing about positive behavioural change according to Craig (1990) in Adedokun (1998) will lead to reconstruction and reorganization of experiences which add meaning to experiences and which increase the ability to direct the course of subsequent experience (p. 41); help people to see things clearly, distinguish between essentials and trivial, thereby, giving people the right frame of mind to judge between rumours and sound and positive information thus, helping them to build positive attitudes to the on-going awareness programmes and preventive measures on COVID-19.

Education will make people aware of what is going on in their environment. This is the emphasis of Freire's 'Conscientization' policy that the pessimistic and fatalistic attitudes of people about their environment can change only through the process of awareness (Freire, 1972).

\subsection{Objectives of the Study}

The study is aimed at finding out about:

1) Awareness programmes that are embarked upon in Oyo State, Nigeria.

2) The medium of information about COVID-19 in Oyo State, Nigeria.

3) The Perception of people on preventive measures aimed at containing COVID-19 pandemic.

4) The relationship between preventive measures on COVID-19 and citizen compliance.

\subsection{Research Questions}

The following questions were raised for the study:

1) What are the awareness programmes on COVID-19 in Ibadan North Local Government of Oyo State, Nigeria?

2) What are the mediums/media of information on COVID-19 in Ibadan North Local Government of Oyo State, Nigeria?

3) What are the perceptions of people of Ibadan North Local Government of Oyo State on preventive measures to contain COVID-19 pandemic?

4) Do citizens comply with COVID-19 preventive measures in Ibadan North Local Government area of Oyo State?

\subsection{Hypotheses}

The following hypotheses were generated for the study:

1) There is no significant relationship between awareness programmes/preventive measures on COVID-19 and compliance of citizens.

2) There is no significant relationship between medium/media of information on COVID-19 and compliance with preventive measures.

3) There is no significant relationship between perception of citizens on awareness programmes/preventive measures and citizens' compliance.

4) Awareness programmes, medium of information and perception of citizens on COVID-19 will not predict the compliance of citizens with awareness programmes/preventive measures in Ibadan North Local Government area of Oyo State, Nigeria. 


\subsection{Significance}

The study is significant to the extent that it emphasizes the importance of awareness programmes on everyday healthy living especially during the period when the world is going through hard times on COVID-19. The awareness programmes would pave way for healthier living with subsequent higher living standard that could lead to economic well being of individuals and the nation at large to the extent that wastage of human resources would be minimized.

\section{Corona Virus (COVID-19)}

Coronavirus which is tagged COVID-19 is the trending pandemic in nations of the world, biting hard on both the young and old, the rich and the poor. It is neither age bound nor boundary specific and unfortunately with no specific cure for it at the moment; though people carry a lot of rumours about its cure using some medications such as hydroxychloroquine, Azithromycin, Zinc sulphateamong others. Some other people believe in the use of herbal mixtures for its cure such as a mixture of lemon, with ginger and garlic, taking hot water at intervals and many news about its cure trending on social media.

Coronaviruses are a family of viruses that can cause illnesses such as the common cold, severe acute respiratory syndrome (SARS) and Middle East Respiratory Syndrome (MERS) (MyoClinic Staff, 2019). The new trending disease since 2019 is called the Severe Acute Respiratory Syndrome Coronavirus of (SARS-COV 2). It was in March 2020 that the World Health Organization (WHO) declared the COVID-19 outbreak, a pandemic (World Health Organization,2020) and this was followed by close monitoring of the spread of the disease by Public Health groups in all nations of the world including the U.S. Centres for Disease Control and Prevention (CDC), World Health Organization and the Nigeria Centre for Disease Control (NCDC) in Nigeria. To make the monitoring effective, each state of the Nigeria sets up its own arm of the NCDC, while WHO reports updates daily. Nigeria, through NCDC makes its updates known to Nigerians to disinfect their minds of the rumour that COVID-19 is not real.

WHO (2020) embarks on massive awareness programmes on COVID-19 through its websites, while NCDC also embarks on massive awareness through media, social networks and person to person information based on the various vital educative information from the World Health Organization(WHO).

The World Health Organization (WHO) made some points clear about COVID-19 in order to lessen the spread of the disease. This includes statements about the signs and symptoms of the disease which include, headache, dry cough, fever, tiredness and difficulty in breathing, sore throat, loss of taste and smell among others. It was stated that the virus could spread through droplets from infected persons to others, touching surfaces and not maintaining adequate social distancing and which could lead to a lot of other complications like heart and liver failure and other organ failures especially among people with underlying diseases before contacting the COVID-19. This explanation is important in a country like Nigeria where social gathering and events occur regularly.

The first case of COVID-19 in Nigeria was announced on 27th February with an Italian testing positive for the virus in Lagos (Maclean, Ruth, \&Dihir, 2020). A second case was found in Ewekoro, Ogun State in a Nigerian citizen who had contact with the Italian citizen (PM News, 2020). These cases were put in isolation and by their testing positive, they were quarantined.

Prior to the discovering of these COVID-19 patients, the Federal Government of Nigeria had made concerted efforts towards containing the disease by setting up various committees that would work towards its containment by setting up the Nigeria Centre for Disease Control (NCDC) (Odunsi, 2020).

On 22 March, the first case of coronavirus surfaced in Oyo State, Nigeria (Ala, 2020). Ever since this first date of the confirmed case, there had been an increase in the number of cases discovered in Oyo State with many of the cases coming from Ibadan, the capital city of Oyo State.

With daily increase in the number of coronavirus cases, President Muhammadu Buhari established a Presidential Task Force to deal with the rising cases (Terhemba, 2020). The task force was saddled with the responsibility of preparing for the unlikely public outbreak of the disease and that this would require a multi-sectional and inter-governmental approach. This implies that government at all levels must be on the watch. This made each state government to establish its own-task force; Oyo State inclusive with each local government making efforts at reducing the risk involved in the disease onpeople.

The formation of the task force has witnessed a lot of awareness programmes, preventive and palliative measures not only by the Federal Government but also by the state and local government areas around the country. Such awareness programmes include making people believe that there is a disease called coronavirus and that no 
effective medication had been discovered to cure it in line with the directives of World Health Organization (WHO, 2020), the government at all levels embarked on a process of education on the symptoms of the disease and the need to seek urgent medical attention. People were also educated on various preventive measures as laid down by WHO. Such as maintaining social distancing, wearing of face masks, putting in use of alcohol-based sanitizer.

The nations of the world were warned by Tedros Adhanoun Ghebreyesus, the Director General, World Health Organization by stating:

"We're deeply concerned by the alarming levels of spread (of COVID-19) and security and by the alarming level of inaction. We have rung the alarm bell loud and clear." (WHO, 2020,n.p.)

With this important alarm raised on COVID-19, many Nigerians still believe that the disease is non-existent and people who are mostly susceptive to various underlying diseases that could lead to complications such as older people with underlying medical problems like cardiovascular disease, diabetes, chronic respiratory disease and cancer are not aware of those underlying diseases due to their state of poverty which made it difficult for many to access medical facilities/treatment.

Most people in Nigeria and inthe local government under study and Oyo State in generalbelieve that the outcry is another design of the government to sap the funds of the country and bring in their hidden agenda and thus, putting on lackadaisical attitude to the alarm on the disease. Some who believe that the disease exists hold fast to the fact that they cannot contact the disease not minding the low level of their immunity while many believe that with local herbs, shrubs and roots, the disease could be cured without seeking medical attention basing their claims on herbal curative measures flying on social media; not really trying to find out the authenticity of such claims.

Due to the above assumptions, the government at all levels intensified their awareness programmes and preventive measures, distributing preventive items like sanitizers, face masks and other protective equipments and taking further steps to minimize the spread by putting in place lock downs,ban on interstate travels, ban on social gatherings, school closure, regulating banking hours and market days and putting curfew from dusk to dawn in placein all the states of the country.

All these were put in place in Oyo State generally until when the Governor of the state eased down the lock down orders (Adejumo, 2020). Prior to the ease of the lockdown orders, the cases were not many but following the ease, the case of corona virus patients shot up.

This might be as a result of people flouting the various preventive measures and disregarding the continuing awareness on the disease as NCDC, and daily updates of those infected in the country.

\subsection{Awareness Programmes on COVID-19}

Awareness programmes involve enlightenment on the causes, prevention and efficient management of any discovered disease. Awareness programmes are likely to prune down the fast spread of diseases when the programmes are effective on people. Through awareness campaign, people would be made aware of the symptoms of the disease, which could lead to early diagnosis of which curative activities would be embarked upon to stop the spread of the disease. Olowookere (2019) believes that raising awareness in people in the case of any epidemic outbreak is vital to nation building because good health is germane to economic development of any nation and this implies educating the Nigerian population about the disease.

Ferretti, Wymat, Kendell and Zhao (2020) express strongly in their study that SARS COV-2 is more infectious than the earlier SARS-COV-1 which started in China in 2002. They opined that with no effectivetreatmentfound; the spread of the epidemic can be reduced if not stopped through adequate information dissemination regarding the various ways of the transmission of the disease and that good plans of action should be put in place to cure and control the spread of the disease. They thus, proposed an application which is based on phone (technology) which could be used for instant contact tracing to alert those who had come in contact of the risk of the virus and immediately go into isolation. They were of the opinion that contact tracing could help in containing the disease. The authors lend credence to the fact that around half of infected individuals are reported with intensive care support. This implies that many cases remain unreported. In Nigeria, many cases remain unreported due to the fact that people are scared of going forCOVID-19 test because of the fear of being positive.

Dryhurst, Claudia, Schneider, Karr, Alexandra, Freeman and Bless (2020) express that, the disease, COVID-19 is influenced by people's willingness to adopt prevention health behavior. With samples taken around the world totaling 6,991, in ten countries from America, Asia and Europe, their study which was on perception of the virus around the world, found that there are various ways to perceiving the disease which can be from personal 
experience with the various individualistic and pre-social values, hearing about the disease from friends and finally trust in government, science and medical professionals and knowledge of government strategy as well as personal and collective efficacy are significant predictions of risk perceptions. They found in their study that risk perception correlated significantly with reported adoption of preventive health behaviours in all the countries of their study. To them government responses range from social distancing and hygiene advice. When people perceive the risks involved in the epidemic and have knowledge of the way by which it spreads, there must be a positive change in behaviour, in order not to be infected. This calls for taking personal responsibility through positive change in behaviour because it can lessen the spread of the disease.

Funk, Gilead, Watkins and Jansen (2009) believe that in situations where there is yet to be any authentic information about the presence of any disease, awareness could be raised through first hand observation and word of mouth which can be from one person to another; believing that this can lower the size of the outbreak and that if the behavioural response is treated locally in proximity of the outbreak, it can put a stop to the spread; however, this is if the infection rate is below a threshold/outset of the pandemic. They however believe that the containment does not only call for locally spreading awareness but for overlapping of social networks in which people communicate. Philipson (1996) believes that people's positive behavior in case of epidemic outbreak will be tied to the level of awareness created on the presence of the disease. He stated clearly that people need not adopt protection behaviour only when they see people die of the disease but by being adequately informed about its existence.

Taiz (2007) expresses that with the outbreak of severe acute respiratory syndrome (SARS) in China, 2003, awareness about the outbreak was sent in form of text massages to millions of people hence, people took necessary precautions in order to cut short the spread of the virus. Awareness is very important in curbing the spread of any identified disease and in this case the use of phones and other social media could be of great help.

People especially in Nigeria and in the area of study rely more on rumours than authentic information on the virus hence the rapid spread. Nekovee, Moreno, Bianconi and Marsili (2007) state that rumour is an infection of the mind which implies the mind is contagious. As fake information is passed from person to person, there is bound to be loss of quality and authenticity in the information being passed, thereby misleading people about the operation of the disease and making containment a herculean task. Awareness is, being in possession of real information about anything especially about the outbreak of a disease as it is in COVID-19 in this study. Awareness should input in people the willingness to take immediate actions to put a stop to the disease or reduce their susceptibility to it.

Funk et al. (2009) believe that information should spread quickly at an alarming rate to have effect on the people so that the informed people will not be infected. This is the essence of community education as people would be sensitized and become conscientized about what is happening in their environment and take precautionary steps against any epidemic. Funk et al. submit through their findings that the spread of awareness on a contagious disease can lead to a reduction in susceptibility of individuals to the disease and can as well reduce its spread but that this does not mean it would not reach an epidemic/pandemic stage; but that with adequate information andwide spread awareness programmes, the infection rate can be significantly reduced.

Zuo and Liu (2014) in their study "effect of awareness programmes as driven by media on the prevention of an infectious disease" found that when there is increasing rate of awareness on an epidemic it is likely there is a reduction in the proportion of infected population. They submit that media is germane for influencing people's behaviour towards an epidemic and that through awareness programmes on media, people are likely to take positive steps towards not being infected. Gao and Ruan (2011) believe that media coverage plays essential roles in the containment of infectious disease but will be effective with people's willingness to change their behaviour in line with the preventive measures of the disease.

Misra, Sharma and Shukla (2011) in their study proposed a non-linear mathematical model for the effects of awareness programmes on the spread of contagious disease and found that infectious disease can be halted from spreading through flouting various awareness programmes. Guihua and Don (2019) examined the use of public health education, mass and interpersonal communication on the effective control of infectious disease. The study reveals that various educational activities and public health education are valuable activities that could lead to reduction in the spread of a disease. People, both rich and poor, young and old, should not give up on healthy practices and put preventive measures into practice while being optimistic that hard times of the COVID-19 will pass and that what people are passing through now are beneficial to themselves, to others around them and the society at large and that the mental preparedness individuals take at the time of COVID-19 pandemic makes a difference. Thus, people should develop positive attitudes and behaviour to the ongoing pandemic. 


\subsection{Statement of the Problem}

There is no gainsay that COVID-19 is a pandemic ravaging the world since 2019. However, it is observed that some people are in attentive to the havoc it is wrecking in societies of the world hence, some people hold on to their belief that the disease is non-existent. With this frame of mind, it is observed that many people are not taking various and incessant awareness programmes and preventive measures put in place very serious. This study was set to examine the awareness programmes and preventive measures on COVID-19 and the level of compliance of the people of Ibadan North Local Government are ofOyo State, Nigeria, to the programmes.

\section{Methodology}

The study was carried out in Ibadan North Local Government area ofOyo State, Nigeria which houses three major markets and two higher institutions of learning, the University of Ibadan founded in 1948 and the Polytechnic, Ibadan founded in 1970. The local government area has 12 political wards. Six wards were purposively selected for the study.

The study was carried out through the use of well-structured self-designed questionnaire titled "Questionnaire on Awareness Programmes/Preventive Measures on COVID-19/People's Compliance” (QAPPM-C-19/PC). This was administered through the Google form. The study employed a descriptive research of the survey type. The population for the study consisted of people of Ibadan North local government area and the target age was from 25-60 years and who could assess the form on the google/whatsApp pages and resident inthe local government used for the study. Each of the authors sent the form to those within the stipulated age group and who could assess the form. The collation from the authors was done and only the forms that were fully filled and valid totaled 200 and these were used for the study.

\subsection{Sample}

Purposive Sampling was used to send questionnaire to people in the age range above on the contact list of the authors. 400 respondents were selected out of which 200 completed filling the form in a valid way.

\subsection{Instrument}

The research questions were analyzed making use of Mean and standard deviation with remarks indicated. Hypotheses 1-3 were analyzed making use of T-test statistical tool while hypothesis 4 was analyzed with ordinary least squares regression.

\subsection{Limitation}

The study is not without its limitations in the area of questionnaire retrieval. Due to lack of facial contact with respondents, some were not able to complete the set of questionnaire sent and this might be due to doubt as to how they perceive the pandemic and their belief about it. It might also be due to inattention paid to awareness programmes and preventive measures on the pandemic.

\section{Results}

Research Questions 1: What are the available awareness programmes on COVID-19 in Ibadan North Local Government of Oyo State, Nigeria?

Table 1. Awareness programmes on COVID-19 in Ibadan, Oyo State

\begin{tabular}{|c|c|c|c|c|c|}
\hline & & $\mathbf{N}$ & Mean & Std. Deviation & Remarks \\
\hline 1. & Covid-19 is real in Oyo State & 200 & 3.90 & 1.182 & 6th \\
\hline 2. & $\begin{array}{l}\text { Awareness of government restriction on mass gathering with more than } \\
20 \text { people to prevent Covid-19 }\end{array}$ & 200 & 4.93 & .264 & 4th \\
\hline 3. & Adequate knowledge of wearing of mask while in public places. & 200 & 4.90 & .301 & 6 th \\
\hline 4. & Update on number of Covid-19 infected persons in on a daily basis & 200 & 3.39 & .987 & 4 th \\
\hline 5. & $\begin{array}{l}\text { Knowledge of temporary restriction on religious centres with strict } \\
\text { adherence to guidelines to contain Covid-19 }\end{array}$ & 200 & 4.84 & .419 & 7 th \\
\hline 6. & $\begin{array}{l}\text { Awareness of government banning of night clubs and interstate travel } \\
\text { except for essential goods. }\end{array}$ & 200 & 4.69 & .563 & 8 th \\
\hline 7. & Government imposed dusk to dawn curfew. & 200 & 4.91 & .294 & 5 th \\
\hline 8. & $\begin{array}{l}\text { Government placed limit on wedding and funerals services to } 20 \text { people } \\
\text { in order to reduce the spread of Covid- } 19 \text {. }\end{array}$ & 200 & 4.96 & .208 & $3 \mathrm{rd}$ \\
\hline 9. & $\begin{array}{l}\text { Government mandates the use of hand washing and sanitizers to prevent } \\
\text { Covid-19 }\end{array}$ & 200 & 5.00 & $.000 *$ & $1 \mathrm{st}$ \\
\hline 10. & $\begin{array}{l}\text { Government mandates closure of schools, bars and restaurants to contain } \\
\text { the spread of Covid-19 }\end{array}$ & 200 & 4.97 & .184 & 2 nd \\
\hline
\end{tabular}


Table 1 reveals that items 9 ranks first with mean score of 5.00 which means people are much aware of the use of hand washing and sanitizers to prevent being infected with COVID-19. Item 10 ranks second (4.97) as children of school ages stay home perpetually. Item 8 ranks third with means score of 4.96. Oyo state is a social state where social events take place often, hence, they are hard hit by the awareness put upon social gathering. Item 6 ranks 8 th with the mean score of 4.69 . This is likely to be because some recalcitrant persons still find ways to travel out of their places of abode cutting corners in the process of their travel. Above all, people of Ibadan North local government area are much aware of the various programmes of awareness and preventive measures put up by the government of Oyo state and the local government under study.

Research Question 2: What are the media of information about the awareness of and existence of COVID-19?

Table 2. Medium of information on Covid-19

\begin{tabular}{|c|c|c|c|c|c|}
\hline & & $\mathbf{N}$ & Mean & Std. Deviation & Remarks \\
\hline 1. & I listen to Orientation on COVID-19 through Television & 200 & 1.40 & .491 & 4 th \\
\hline 2. & I listen to Orientation on COVID-19 through Radio & 200 & 1.10 & .264 & 5 th \\
\hline 3. & I watch awareness on COVID-19 through social media & 200 & 1.85 & .358 & $1 \mathrm{st}$ \\
\hline 4. & I listen to COVID-19 preventive measure through the community interaction & 200 & 1.58 & .496 & 2nd \\
\hline 5. & I receive information on COVID-19 through Government enlightenment & 200 & 1.45 & .498 & $3 \mathrm{rd}$ \\
\hline
\end{tabular}

Table 2 reveals that many people are aware of COVID-19 on social media technology such as Facebook, WhatsApp, YouTube and instagram to mention but a few so item 3 with a mean score of 1.85 ranks 1 st, item 4 ranks 2 nd, item 5 ranks 3rd, item 1 ranks 4 th, while item 2 ranks 5 th. The first ranking (1.85)shows that majority of the respondents were glued to their mobile phones on which they could access ready information without being glued to a sport like having to watch television before listening to information on Covid-19.

Research Question 3: What is the perception of citizens on preventive measures to containing Covid-19 pandemic?

Table 3. Preventive measures for COVID-19 pandemic

\begin{tabular}{|c|c|c|c|c|c|}
\hline & & $\mathbf{N}$ & Mean & Std. Deviation & Remarks \\
\hline 1. & If I take herbal medicine, I cannot contact COVID-19 & 200 & 3.36 & 1.103 & 7th \\
\hline 2. & Wearing face mask can prevent me from contacting the disease & 200 & 3.51 & .862 & 2nd \\
\hline 3. & Wearing face mask makes me uncomfortable & 200 & 3.37 & .909 & 6th \\
\hline 4. & $\begin{array}{l}\text { Regular washing of hands with soap under running water can prevent me } \\
\text { from contacting the disease }\end{array}$ & 200 & 3.42 & .953 & 4 th \\
\hline 5. & Alcohol based sanitizer can help prevent me from contacting the disease & 200 & 3.63 & .746 & $1 \mathrm{st}$ \\
\hline 6. & Only God can keep me from contacting COVID-19 & 200 & 3.31 & 1.148 & 8 th \\
\hline 7. & $\begin{array}{l}\text { Buckets with water and soap and sanitizers are provided in shops, banks } \\
\text { and market places }\end{array}$ & 200 & 3.38 & .933 & 5 th \\
\hline 8. & $\begin{array}{l}\text { I keep my distance from people when in markets, banks and other public } \\
\text { places }\end{array}$ & 200 & 3.00 & 1.248 & 9th \\
\hline 9. & I have refrained myself from visiting people & 200 & 3.45 & 1.006 & $3 \mathrm{rd}$ \\
\hline
\end{tabular}

Table 3 shows item 5 ranking 1st, item 2 ranks 2nd, item 8 ranks 3rd, item 4 ranks 4 th, item 7 rants 5 th, item 3 ranks 6 th, item 1 ranks 7 th, item 6 ranks 8 th while item 8 with a mean score of 1.248 ranks 9 th. The table reveals the belief of people in the use of hand sanitizer (3.63) while item 8 ranks 9th because people found it very difficult to maintain social distance in open markets and banks and otherpublic places.

Research Question 4: Do citizens comply with COVID-19 Preventive measures? 
Table 4. Compliance of citizens on COVID-19 preventive measures in Ibadan North local government, Oyo

State

\begin{tabular}{|c|c|c|c|c|c|}
\hline & & $\mathbf{N}$ & Mean & Std. Deviation & Remarks \\
\hline 1. & Regularly listening to the news update on the spread of Covid-19 & 200 & 3.83 & 1.257 & 8 th \\
\hline 2. & $\begin{array}{l}\text { Regularly staying away from more than } 20 \text { people gathering to prevent the risk } \\
\text { of Covid-19 }\end{array}$ & 200 & 4.57 & .662 & 4th \\
\hline 3. & $\begin{array}{l}\text { Wearing of mask regularly to the public places to prevent the risk of Covid-19 } \\
\text { infection. }\end{array}$ & 200 & 4.10 & 1.244 & 7 th \\
\hline 4. & No longer going to religious centres because of Covid-19 infections. & 200 & 4.90 & .301 & 1 st \\
\hline 5. & $\begin{array}{l}\text { Postponing travelling schedules to other states to prevent the risk of contacting } \\
\text { Covid-19 }\end{array}$ & 200 & 4.53 & .896 & 5 th \\
\hline 6. & Not attending wedding and funerals to prevent the risk of Covid-19 & 200 & 4.75 & .549 & $3 \mathrm{rd}$ \\
\hline 7. & Washing of hands with soap and sanitizer to prevent the risk of Covid-19 & 200 & 4.80 & .511 & 2nd \\
\hline 8. & Restraining my family from visitation. & 200 & 4.28 & 1.174 & 6th \\
\hline
\end{tabular}

Table 4 shows item 4 ranking 1st with a mean of 4.90. Item 7 with a mean score of 4.80 ranked 2nd, item 6 (4.75) ranked 3rd, item 2 (4.57) ranked 4th, item 5 (4.53) ranked 5th, item 8 ranked 6th (4.28), item 1 ranked 8th (3.83), while item 3 (4.10) ranked 7th.

Hypothesis 1: There is no significant relationship between awareness of Covid-19 preventive measures and compliance of citizens

Table 5. Relationship between awareness programmes/preventive measures on Covid-19 and compliance of citizens

\begin{tabular}{llllllll}
\hline & $\mathbf{N}$ & Mean & SD & Df & Cal r-val & P-val $_{\text {- }}$ & Decision \\
\hline Awareness/Prevention measure & 200 & 47.0000 & 3.86454 & & & & \\
Compliance & 200 & 35.7450 & 6.21960 & 198 & 0.975 & 0.000 & Significant \\
\hline
\end{tabular}

Data contained in Table 5 show that there exists strong and positive significant relationship between awareness of Covid-19/preventive measures and compliance of citizens in Ibadan North local Government area of Oyo State at 0.05 level of significance $(r=0.975, \mathrm{p}=.000<0.05)$. The null hypothesis was rejected. This implies that a unit increase in citizen's level of awareness will simultaneously improve their compliance. Therefore, there is significant relationship between awareness Programmes on Covid-19/preventive measures and compliance of citizen.

Hypothesis 2: There is no significant relationship between medium of Awareness/Preventive measures on Covid-19 and compliance of citizens

Table 6. Relationship between medium of awareness programmes/preventive measures on Covid-19 and compliance of citizens

\begin{tabular}{llllllll}
\hline & N & Mean & SD & df & Cal r-val & P-val & Decision \\
\hline Medium of information & 200 & 7.3700 & 1.70223 & & & & \\
Compliance & 200 & 35.7450 & 6.21960 & 198 & -0.811 & 0.000 & Significant \\
\hline
\end{tabular}

Table 6 shows that there exists low significant relationship between medium of information on Covid-19 preventive measures and compliance of citizens in Ibadan North Local Government area of Oyo state at 0.05 level of significance $(\mathrm{r}=0.811, \mathrm{p}=.000<0.05)$. The null hypothesis was rejected. This implies that the low relationship in the result might be due to some forms ofdeficiency in some channels of information and this may be as a result of a unit decrease in citizen's medium of information which will simultaneously reduce their compliance.

Hypothesis 3: There is no significant relationship between perception of citizens on preventive measures and compliance on Covid-19. 
Table 7. Relationship between perception of citizens on preventive measures and compliance on Covid-19

\begin{tabular}{llllllll}
\hline & $\mathbf{N}$ & Mean & SD & Df & Cal r-val & P- $_{\text {val }}$ & Decision \\
\hline Perception of citizen on Awareness & 200 & 30.4100 & 8.57611 & & & & \\
Compliance & 200 & 35.7450 & 6.21960 & 198 & 0.983 & 0.000 & Significant \\
\hline
\end{tabular}

Table 7 shows that people have a high perception of awareness programmes/preventive measures of Covid-19 and thus having a significant relationship with their compliance $(\mathrm{r}=0.983, \mathrm{P}=.000<0.05)$. The hypothesis was rejected. This implies that a unit increase in the perception of people of will simultaneously increase their compliance level. As people perceive truth in the awareness programmmes/preventive measures on Covid-19, they made efforts to comply.

Hypothesis 4: All the three variables (Awareness, medium of information and perception of citizens) will not predict the compliance of citizen on Covid-19 preventive measures.

Table 8. Ordinary least squares regression of the effect of awareness, medium of information and preventive measure on compliance level

\begin{tabular}{|c|c|c|c|c|c|}
\hline \multirow[b]{2}{*}{ Model } & \multicolumn{2}{|c|}{ Unstandardized Coefficients } & \multirow{2}{*}{$\begin{array}{l}\text { Standardized Coefficients } \\
\text { Beta }\end{array}$} & \multirow[b]{2}{*}{$\mathbf{T}$} & \multirow[b]{2}{*}{ Sig. } \\
\hline & B & Std. Error & & & \\
\hline (Constant) & -7565 & 1.752 & & -4.319 & .000 \\
\hline Awareness & .669 & .043 & .416 & 15.514 & .000 \\
\hline Medium of Information & -.094 & .052 & -.026 & -1.800 & .073 \\
\hline Preventive Measure & .413 & .019 & .570 & 21.654 & .000 \\
\hline
\end{tabular}

Note. a. Dependent Variable: Compliance

${ }^{*} \mathrm{p}<0.05, \mathrm{R}=0.993 \mathrm{R}^{2}=0.976$; Adjusted $\mathrm{R}^{2}=0.986 ; \mathrm{F}=4707.2 ; \mathrm{Sig}=0.000$.

Table 4 revealed that $\mathrm{F}=4707.2, \mathrm{p}<0.05$ level of significance. The null hypothesis is rejected. Therefore, independent variables (awareness, medium of information and preventive measures) put together predict the level of compliance among the citizens in Ibadan North Local Government area of Oyo state. Also, the result indicated that independent variables put together contributed $7.56 \%\left(\mathrm{R}^{2} \times 100\right)$ of variance in the determinant of compliance to contain the Covid-19 among citizens. The coefficient output revealed that preventive measures has the highest (Beta Weight $=0.570$ ) contribution to compliance level. This is closely followed by awareness (Beta weight $=0.416)$, medium of information $($ Beta Weight $=0.026)$ in order of contribution coefficient. The table further showed that there is positive multiple correlation between the predictor variables and compliance $(\mathrm{R}=0993)$. This implies that all the predictor variables are factors that can contribute to the compliance level on covid-19 preventive measures. The value of coefficient of determinant $\left(\mathrm{R}^{2}=0.986\right)$ indicated that all the predictor variables jointly accounted for $98.6 \%$ of the total variance in the compliance of citizens on Covid- 19 preventive measures in Ibadan North Local Government area of Oyo state but preventive measures have the highest contributions out of all the variables.

Awareness has a positive relationship with compliance level among the citizens under study. A unit increase in awareness will lead to 41.6 percent increase in compliance level among the citizens and this is significant at 1 percent. It implies that as awareness increases compliance is likely to increase among the citizens.

Medium of information has a negative relationship with compliance level among the citizens of Oyo state. An increase in medium of information will lead to 2.6 percent decrease in compliance level among the citizens. It is significant at 10 percent. It reveals that as medium of information increases, compliance level decreases among the citizens. This might be due to proliferation of fake, and unverified and uncertified news.

Preventive measures have positive relationship with compliance levels among the citizens of Oyo state. An increase in preventive measures will lead to 57.0 percent increase in compliance levels among the citizens. It is significant at 1 percent. It indicated that as preventive measures increase compliance level increases among the citizens.

\section{Discussion}

The study showed that there was a strong and positive significant relationship between awareness programmes/preventive measures and people's compliance with these measures. This might be a result of the fact that Nigerians generally would not have paid much attention to COVID-19 awareness/preventive measures (especially at the inception of the pandemic in Nigeria) but seeing highly placed government officials dying due 
to COVID-19, efforts were made by individuals within the state and Nigeria in general to be more responsive to warnings as they are being flouted on awareness programmes and they started paying more attention to preventive measures; though with incessant complaints about face mask making them uncomfortable. This finding is in line with the findings of Zuo and Liu (2014) that when there is increasing rate of awareness and quick dissemination of information and preventive measures on any epidemic, there can be reduction in the number of people infected. Now that COVID-19 pandemic is at the community spread level, people must take personal responsibility towards containment of the pandemic. Gao and Ruan (2011) also subscribe to the fact that the spread of infectious disease can be controlled through vigorous awareness programmes but that through the process of immigration it can become endemic. This is the case in Nigeria where thousands of youths migrate under dubious means, for example, by hiding under cows and food stuff from the northern part of the country to the southern part making the disease to spread more despite ban on interstate travel.

The study showed that there exists low significant relationship between medium of information on COVID-19 on awareness programme/preventive measures and citizens' compliance as seen in $(\mathrm{r}=0.811, \mathrm{P}=000<0.05)$. This is likely to be as a result of proliferation of unverified fake news from social media and from one person to another. Such news is neither verified nor certified by relevant organizations such as World Health Organization (WHO) nor the Nigeria Centre for Disease Control (NCDC). However, previous studies by Gao and Ruan (2014) state expressly that media coverage have a lot of roles to play in containing the spread of infectious disease. Care must however, be taken to verify news on social media concerning the pandemic. This finding is in line with the exposition and warningof UNESCO (2020) on "fake news" in the time of COVID-19.

UNESCO (2020) states, "since the beginning of the COVID-19 pandemic, we have seen parallel outbreaks of disinformation and misinformation about the virus, ranging from fake corona virus cure, false claims and harmful advice to wild conspiracy theories".(n.p.)

UNESCO is quick to add that "disinformation can in turn speed up the spread of the disease, hinder effective public health responses, as well as create confusion, fear and distrust".(n.p.)

The influence of fake news has compounded every effort at containing the pandemic. However, though some fake news spread through media outlets, one can still find authentic newsthrough these media. This is in line with the findings of Taiz and Sun (2007)that at the outbreak of SARS in China 2003, text messages were used to make people aware of the dangers inherent in the new disease and through text messages, they were advised to take precautionary measures; Zuo and Liu (2014) were also of the opinion that media play important roles in influencing people's behaviour during an outbreak of disease, Giuhua and Don (2019) also subscribe to the use of mass media when there is an outbreak of infectious disease; to make people aware of the disease, how it spreads and preventive measures to take in order to keep safe. People must, however, play safe on the authenticity of news they listen to.

Chao et al. (2018) in Ahikorah, Ameyaw, Hagan, Seidu and Schack (2020), rated that fake news otherwise termed as misinformation amounts to any claim that lacks scientificbacking and that the instance of fake news may lead people to becomefearful and worrisome about the mode of transmission of COVID-19. People's minds must, therefore, be disinfected from fake news by seeking valid information from authoritative sources and health care givers.

The result of this study showed a significant relationship between perceptions of citizens on awareness programmes/preventive measures on Covid-19 and their compliance level $(\mathrm{r}=0.983, \mathrm{P}=0.000<0.05)$. The respondents perceived that COVID-19 could be a great threat to healthy living hence, adherence to preventive measures, even though their level of perception was hindered by fake news. Perceiving the risk in contacting Covid-19, calls for change in behaviour as found in the study of Philipson (1996) that there is a need for change in behaviour after being informed and made aware of the disease. Such changes include maintaining social distancing, avoiding contact with infected person, wearing protective masks especially when outdoors, keeping in-doors as much as possible and avoiding crowded gatherings. The perception of people on Covid-19 could improve if according to Nekoveeet al. (2007) "the infection of the mind is improved upon. People should disregard fake news and rumour concerning the disease to be in the right frame of mind and for better perception of the various awareness programmes and preventive measures on Covid-19 and compliance. To improve people's knowledge about the disease and raising compliance level, public education which will ensure self-care practices should be embarked upon. This is in accordance with the findings of Guihua and Don (2019), that various educational activities and public health education could lead people to an in-depth positive perception of the negative effect of Covid-19 on people's health thus, making people all over the world to comply more with preventive measures of the disease. 
Dryhurst, Scheneider, Alexandra, Freeman, Rechhia and Marthe Van de Bless (2020) found that risk perception correlated significantly with adoption of preventive health behaviours while Van Bavel, Bogqio, Capraroet al. (2020) believe that when there are awareness people will change their behaviour and take adequate steps on not being infected, Funk et at. (2020)also called for rapid changes in behaviour as they perceive the risk to health involved in an infectious disease like COVID-19 and this can be done through raising instant awareness through conversation and possibly with words of mouth at inceptions while Philipson (1996) opined that responsive behaviour of people at risk perception of a disease can lessen the spread of such diseases.

The study showed that independent variables of awareness, medium of information and preventive measures predict the level of compliance among the respondents. This implies that awareness programmes, preventive measures and sources of informationby which programmes are disseminated would predict the extent of compliance of people to the programmes of awareness. The study showed that people were open to awareness on COVID-19 through national TV/Radio stations, social media networks, foreign satellite channels which reveal daily, number of confirmed cases, deaths and numbers discharged.

The study showed $\mathrm{F}=4707.2, \mathrm{P}<0.05$ at 0.05 level of significance which indicates that awareness programmes, preventive measures all have impact on people in complying with World Health Organization's warning on Covid-19 and that people with underlyingproblems are at greater risks as seeing in various deaths recorded in Nigeria especially that of the immediate past Governor of the state who passed on, on25 June 2020 and other top government officials in the country.

WHO (2020) disseminates authentic information about the virus; which people assess on the internet, social media and government at the local, state and federal levels also disseminate verifiable information on COVID-19 and how to prevent being infected. The spread of awareness and preventive measures throughmedia sources were emphasized by authors such as Ferretti, Wymat, Kendell and Zhao (2020) recommending the use of existing technology (Phone) for instant tracing, Misra, Sharma and Shukla, (2011) found in their study that the spread of infectious disease can becontrolled by using awareness programmes which will bring along with it preventive measures. Lizia and Maozing (2014), Guihua and Don (2019) submitted in their various studies that media, mass and interpersonal communication, educational activities and public health education are germane to the reduction of infectious diseases. Fake news should thus, be disregarded for awareness programmes and preventive measures to be meaningful in containing COVID-19.

\section{Conclusion}

The study was carried out on Awareness Programmes/Preventive Measures to examine the level of people's compliance. The study exposed the facts that programmes of awareness/preventive measures, were important to curb the ongoing pandemic and that people need a change of behavior in order to halt the spread of the pandemic The government of Nigeria, Oyo state inclusive had embarked on various programmes to enable people perceive the risk in the disease so as to take responsibility for personal protection against it.Themedia have a lot of role to play in information dissemination on COVID-19 while people should guard their minds against fake news which could lead to thought contagion.

\section{Recommendations}

Based on the findings of the study, the following were recommended.

- That awareness programmes be intensified by the three tiers of the government- local, state and federal governments of Nigeria.

- Government should provide essential personal protective equipments like running water, soaps, sanitizers and simple needed medications to boost people's immunity especially to indigent people and communities.

- Citizens should be educated to comply with hygienic behaviour.

- People should be educated to disregard fake news concerning COVID-19 and listen to authentic news and seek verifiable information on the disease.

- People should have the right frame of mind on the issue of COVID-19 so as to stay safe.

Leslie Martin, a Professor of Psychology at California's La Sierra University states in Markam (2020):

"We have found that many people who live through hard times went on to live long - even though their lives were not stress free by any means.... this ability to think about the hard things one goes through as ultimately beneficial — whether to ourselves or to people we care about or to the society at large — seem to be important." 


\section{Acknowledgements}

Appreciation to every author whose work is contacted for this study.

\section{References}

Adedokun, M.O. (1998). Contributions of Community Education to Sustainable Community Development Projectin Oyo State, 1987-1996. An unpublished Ph.D Thesis. University of Ibadan, Ibadan.

Adejumo, K. (2020). Coronavirus: Makinde reviews. Retrieved fromhttp://curfew.www.premiuntimesng.com/regional/sswouth.net/394420-coronavirus-makinde-reviews-c urfew-in-oyo.htm/

Ahinkorah, B.O., Ameyaw, E.K., Hagan Jr., J.E.,Seidu, A.A.,\& Schack, T. (2020).Rising above misinformation or fake news in Africa: Another strategy to control COVID-19 spread.https://doi.org/10.3389/fcomm.2020.00045

Ala, A. (2020). Coronavirus: Nigeria now has 26 confirmed cases. Retrieved May 26, 2020, fromhttp:/thenationaonline.ng.net/coronavirus-nigeria-now-has-26-conformed-cases-ncdc/

Dryhaurst, S., Claudia, R., Schneider, J.K., Alexandra, L.J., Freeman, G. R., \&Anne, M. V. d. B. (2020).Risk Perceptions of COVID-19 around the world.Journal of Risk Research. https://doi.org/10.1080/13669877.2020.1758193

Ferretti, L., Wymat, C., Kendell, M., \&Zhao,L. (2020). Quantifying SARS-COV-2 transmission suggests epidemic control with digital contact tracing. Science, 368(649), 41-45 https://doi.org/10.1126/science.abb6936

Freire, P. (1972). Pedagogy of the oppressed.Harmonds Worth, Penguin.

Gao, D.,\&Ruan, S. (2011). An SIS patch model with variable transmission coefficients. Mathematical Biosciences,232(2), 110-115.https://doi.org/10.1016/j.mbs.2011.05.001

Li,G. H., \& Don, Y. J. (2019). Dynamic modeling of the impact of public health education on the control of emerging infectious disease. Retrieved May 31, 2020, from http://semanticsscholar.org/paper/Dynamic-modelling-of-the-impact-of-public-health-on-Li-Don/ca64f92f2 fe9e9/afe8305799d/f29c Ob356e5caa

Maclean, R.,\&Dihir, A. (2020). Nigeria responds to first coronavirus case in Sub-Saharan Africa. The New York Times (10 March, 2020).

Markham, H. (2020). What people who live long and through pandemics, Wars and More-Have in common. Retrieved June 2, 2020, from http://elementalmedium.com/what-people-who-live-long-and-through-pandemic-war-and-more-have-in-co mmon- 810/23/5F27

Misra, A.K., Sharma, A.,\& Shukla, J.B. (2011).Modelling and analysis of effects of awareness programmes by media on the spread of infectious diseases. Mathematical and Computer Modelling,53(5-6) 1221-1228.https://doi.org/10.1016/j.mcm.2010.12.005

MyoClinic Staff. (2019). Coronavirus disease (COVID-19) Retrieved May 26, 2020, from http://myoclonic.org/diseases-conditions/coronavirus/symptoms-causes/syn-20479963/

Nekovea, M., Moreno, Y.,Bianconi, G.,\&Marsili, M. (2007).Theory of rumour spreading in complex social networks. PhysicalA,374(1), 457-470.https://doi.org/10.1016/j.physa.2006.07.017

Nigeria Centre for Disease Control. (2020).An update of COVID-19 outbreak in Nigeria. Retrieved May 5, 2020, fromhttp://ncdc.gov.ng/diseases/sitreps17.cat=148name=An\%20update $\% 20$ of $\% 20$ COVID-19\%.20outbreak $\% 20$

Odunsi, W. (2020). Coronavirus, Nigeria announces preventive measures, releases numbers daily.Daily Post Nigeria (10 March, 2020).

Okunnu, O. (2020). Ajimobi burial: Senator AbiolaAjimobi, Oyo ex-Governor die for coronavirus complication. Retrieved July 12, 2020, from http://www.bbc.can/pidgun/tori-53170564

Olowookere, D. (2019). Key Stone Bank, NGOs intensify sickle cell awareness.Businesspost. Retrieved June 2, 2020, from http://ng/health/keystone-bank-ngos-intensify-sickle-cell-awareness

Phillipson, T. (1996). Private Vaccinations and Public Health: An empirical examination for U.S measles. 
Journal of Human Resources,31, 611-630.https://doi.org/10.2307/146268

PM News. (2020). Nigeria records second case of coronavirus.Retrieved May 26, 202, from http://pmnewsnigeria.xom/2020/03/09/breaking-Nigeria-record-secondcase-of-coronavirus/

Funk,S.,Gilead, E., Watkins, E.,\& Vincent, A.A. J. (2009).The spread of awareness and its impact on epidemic outbreak.https://doi.org/10.1073/pnas.0810762106

Taiz, S. T. (2007). Media dependencies in a changing media environment: The case of the 2003 SARS epidemic in China. New Media and Society,9, 987-1010.https://doi.org/10.1177/1461444807082691

Tehemba, D.F. (2020). Buhari names task force on coronavirus. Retrieved May 21, 2020, fromhttp://Guardian.ng.news.buhari-names-task-force-on-corona-virus/

The World Health Organization (WHO). (2020). Retrieved May 21, 2020, from http://Who.int/health-topic/coronavirus\#tab=tab_1/=

UNESCO. (2020).Fake news in the time of COVID-19. Retrieved July 11, 2020, from $\mathrm{http} / /$ Bangkok.unesco.org/index/php/content/press-provides-antidote-fake-news-time-covid-19

World Health Organization (WHO).(2020). Who. Retrieved May 21, from $\mathrm{http}: / /$ int/health-topic/coronavirus\#tab=tab

Zuo, L. X., \& Liu, M. Z. (2014).Effect of awareness programmes as driven by media on epidemic outbreaks with time delay.Abstract and Applied Analysis.https://doi.org/10.1155/2014/940841

\section{Copyrights}

Copyright for this article is retained by the author, with first publication rights granted to the journal.

This is an open-access article distributed under the terms and conditions of the Creative Commons Attribution license (http://creativecommons.org/licenses/by/4.0/). 